PATRICK CRADDOCK is an arts critic and formerly a broadcast journalism lecturer with the University of the South Pacific.

\section{Climate change, media, culture} and the arts

Dreadlocks: Oceans, Islands and Skies, edited by Mohit Prasad. Suva: Pacific Writing Forum, University of the South Pacific; Auckland: Pacific Media Centre. Vol 6/7, 2010/11. 363pp. ISBN 9781927184028

TAPPROACHED this special ediItion of Dreadlocks with caution and apprehension. I saw two interpretations for the title: did it mean embracing science with creative political decisions for change, or did it mean using creativity through the arts as a symbol for approaching climate change?

There is little hard science in these published papers, although there is a view from Richard Dawkins that makes an iconic appearance in a paper by Briar Wood from London Metropolitan University. This emphasises the Dawkins view that scientists must reach out to '...for want of a better word, poets' and that there is a mismatch between science

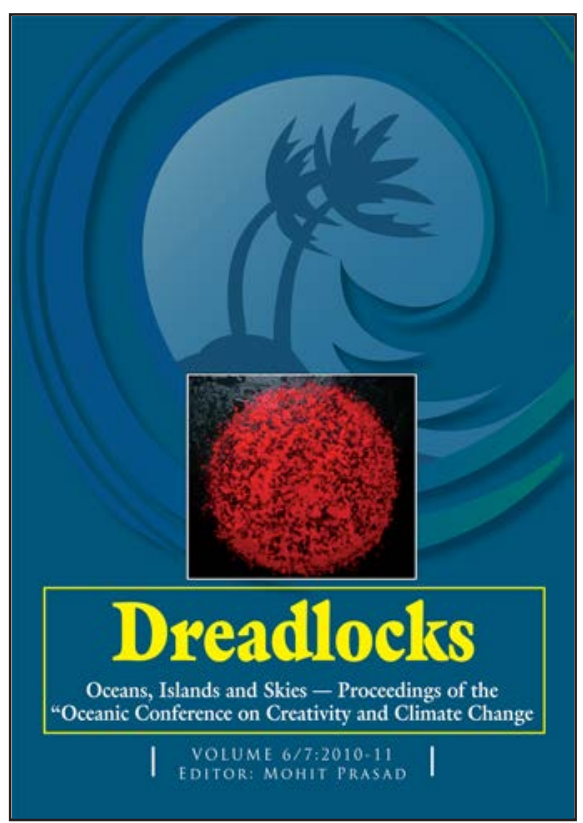

and the metaphorical language used to describe the real world. Improving communication and understanding is a good point to make, although where does climate science meet the arts?

Most of the papers in this publication deal with climate change and its relationship to culture and the arts. The climate metaphors are in abundance. Elizabeth M. DeLoughrey begins her article with the sentence 'Our global warming crisis has increased our solar consciousness.' A few lines later we meet the image of 'the wars of light' followed by Hone Tuwhare's poem No Ordinary Sun.

Manoranjan Mohanty who teaches development studies at the 
University of the South Pacific examines how creativity promotes and enhances environmental values and how the artist relates to sun, ocean, sky, rock, flora and fauna forms to express beliefs and historical knowledge.

Shaiza Janif reflects this historical knowledge with a description of living in small Fijian village communities. Her title 'Narrative of Lost Lands' describes how the sea shoreline has moved closer to the villages until parts of the land are washed away. The author notes that this theft by the sea forms part of the traditional knowledge on what has happened in these communities. Janif says this is a story of how memories of past events affect perceptions of the future. By sharing that knowledge with other vulnerable communities facing climate change, people become efficient at coping with an uncertain future. Janif maintains that her small project showed that powerful memories such as the erosion of the sea on the villages form a tool of history.

Using art for raising awareness on climate change is the theme of Cresantia Frances Koya. She talks of the continuity and survival of story and poetry to develop a discourse on society and the environment. An example is the story of Tuli, a golden lover bird that is said to have been part of creation. Tuli flies, rests and the first island is created. In seeking shelter the first tree appears and when the sacred bird pecks on the vine it rots and a worm appears. This worm is divided and three humans are created.

I found Koya's conclusions both depressing and rewarding. She notes there while there is a general lack of encouragement for the arts in formal education institutions; this is counterbalanced by a strong individual awareness and practice of the arts. Her inclusion of a selection of colored paintings and photographs support this viewpoint.

Ian Gaskell was the foundation professor of theatre arts at USP. He puts a spin on thinking about climate change by evoking the surrealistic and bringing into the discussion the idea of Pataphysics - defined by Alfred Jarry the French writer, as the 'science of imaginary solutions'. Gaskell tells a story of an artist who generated an internet hoax called World Jump Day by creating a phony professor who advocated that 600 million people needed to jump simultaneously at a certain time to shift the Earth's position. With plenty of fans and sceptics, the idea grew well beyond the author's expectations. Gaskell adds to this comedy of life by noting that there is also a desire within us to generate a sense of solidarity against 
what seems to be an unwinnable struggle. He includes his small play One, Two, Three, Jump! and suggests that if anything to be learnt from the characters in his play facing the massive problems of climate change, it may lie in small solutions such as recycling.

Perhaps the most political article in the collection is that by David Robie who writes on the fate of 2700 islanders from the Carteret Islands off the coast of Bougainville, who sadly fit the title of both climate change and environment refugees. By 2015, their atolls may have the unwelcome honour of disappearing under water. With the loss of freshwater and traditional crops the islanders have been forced to move. Robie backgrounds the media response to the Carteret Islanders' story, and also that of Rongelap islanders leaving their homes after nuclear testing. He allows space in his paper to criticise journalists working in mass media who have a preoccupation on the compulsive reporting of events, to the detriment of what he calls comprehensive process journalism. This view, I understand to be well-researched stories written in some depth. The paper includes a 'simple eco journalism code' developed by Kunda Dixit from the Philippines.

Essentially this publication looks at the impact of art and media how they help people remember their cultural values and beliefs and then use this knowledge to inform and persuade them about the impact of climate change on their lives. A touching example in this publication is a study of children in Solomon Islands and the way art helped them cope and adjust after natural tragedies. It's a pity none of their artwork is included in the publication.

I asked myself why there is a paper on Caribbean and not South Pacific tourism? But, I am being petty. Overall this publication makes the reader ponder the many ways that the arts open our minds to our relationship with climate change. The numerous illustrations, most of them in full colour, are stunning. 